\title{
SỬ DỤNG VÒNG VAN TẠO BẰNG DẢI PTFE TRONG PHÃ̃ THUẠT SỬA VAN BA LÁ TẠI BỆNH VIỆN TRUNG UOONG QUÂN ĐỘI 108
}

\author{
Nguyễn Quốc Hung, Hoàng Quốc Toàn*
}

\section{ABSTRACT}

Annuloplastin ring made by PTFE for tricuspid insufficiancy valve repair

Most of secondary tricuspid regurgitation caused by dilation of the tricuspid annulus.

From 2010 to 2011, in 108 hospital, 30 patients with moderate to severe tricuspid regurgitation were repaired with annuloplasty ring made by PTFE.

The surgical outcomes are very encouraging, severe tricuspid regurgitation: 0 patient immediately after operation and 1 patient, 6 months after operation. Tricuspid diameter, right ventricular diameter and pulmonary pressure are improved clearly.

The patient's spending is decrease with this technique.

\section{1. ĐĂT VẤN ĐỀ}

Bệnh lý hở van ba lá rất thường gặp trong bệnh cảnh của bệnh van hai lá và van động mạch chủ.

Trước đây, hở van ba lá nặng chưa được đánh giá đúng mức và thường không được sửa chữa triệt để do suy nghĩ mức độ hở van sẽ giảm khi các tổn thương khác được sửa chữa. Tuy nhiên, một số nghiên cứu gần đây đã chỉ ra rằng mức độ hở van ba lá cải thiện rất kém, thậm chí nặng lên, nếu không được sửa chữa trong mổ (1).

Tại bệnh viện 108 , đáp ứng xu hướng phát triển chung trong vài năm gần đây, vấn đề đánh giá và sửa chữa van ba lá trong các phẫu thuật van hai lá và van động mạch chủ có kèm hở nặng van ba lá đã được tiến hành một cách thường quy.

Các phương pháp sửa van ba lá đã được chúng tôi áp dụng bao gồm: De Vega, Carpentier, DeBonis, nới rộng mô van. Hiện chúng tôi đang áp dụng phương pháp sử dụng dải PTFE tạo vòng van mềm cho van ba lá.

Sau một thời gian triển khai kỹ thuật, chúng tôi tiến hành nghiên cứu này nhằm mục đích: Đánh giá kết quả bước đầu của việc sủ dụng vòng van tạo bằng dải PTFE trong sửa van ba lá.

\footnotetext{
* Bệnh viện Trung ương Quân đội 108
}

\section{2. ĐỐI TƯỢNG VÀ PHƯƠNG PHÁP NGHIÊN CÚU} Đối tượng nghiên cúu.

- Đối tượng bao gồm 30 bệnh nhân được phẫu thuật sửa van ba lá sử dụng vòng van mềm tạo bởi dải PTFE tại bệnh viện TU'QĐ 108 trong hai năm: 2010 và 2011.

- Chỉ đưa vào nghiên cứu các bệnh nhân hở van ba lá trong bệnh lý của van hai lá và van động mạch chủ (có cùng cơ chế hở van ba lá cơ năng do giãn vòng van).

\subsection{Phwơng pháp nghiên cúu:}

- Sử dụng phương pháp nghiên cứu mô tả, sử dụng hồi cứu và tiến cứu.

- Tất cả các bênh nhân trước mổ đều được đánh giá: tiền sử, lâm sàng, siêu âm tim trước mổ. Chọn lựa các bệnh nhân được đánh giá hở van ba lá từ vừa tới nặng trên siêu âm tim trước mổ.

- Phương pháp phẫu thuật:

+ Bệnh nhân được tiến hành sửa van ba lá trong thì tim đập, sau khi đã phẫu thuật trên van hai lá và/hoặc van ĐMC.

+ Đánh giá tình trạng van ba lá trong mổ: đường kính vòng van, độ di động các lá van.

+ Khâu các mũi chỉ Ethibol 2.0, mũi rời trên vòng van ba lá vùng lá trước và lá sau, thường $5-7$ mũi. (hinh 2.1)

+ Sử dụng dải PTFE tạo vòng van mềm, gấp đôi độ dày, chiều dài dải thường là: $7-8 \mathrm{~cm}(2 / 3 \mathrm{chu}$ vi vòng van ba lá bình thường).(hình 2.2)

+ Khâu dải $\mathrm{PTFE}$ vào các mũi chỉ trên van 3 lá và buộc cố định, khi xiết các nút chỉ thường định lượng sao cho diện tích lỗ van lọt vừa 2 ngón tay phẫu thuật viên. (hình 2.3)

+ Kiểm tra kết quả sửa bằng bơm máu ấm buồng thất phải, đánh giá trào ngược. (hình 2.4)

- Đánh giá kết quả sau mổ: Lâm sàng (NYHA), siêu âm (mức độ hở van ba lá, đường kính thất phải, ALĐMPTT).

- Để giảm tỷ lệ sai sót, tất cả các bệnh nhân trong nhóm nghiên cứu của chung tôi đều được làm siêu âm bởi cùng một nhóm bác sỹ và trên cùng một máy siêu âm. 


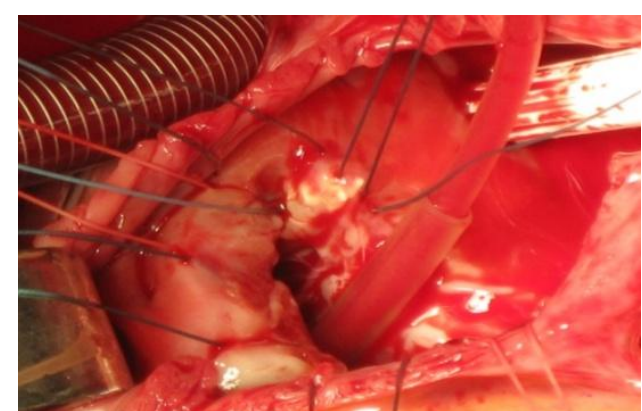

Hình 2.1.khâu các mũi Ethibol 2.0 vùng lá truớc và lá sau

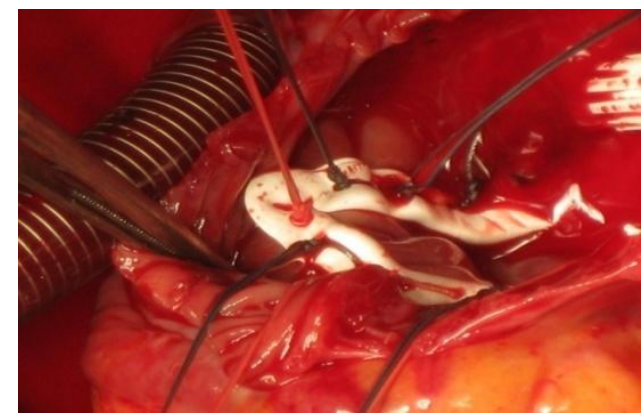

Hình 2.3. Siết chỉ và đánh giá ĐK lỗ van

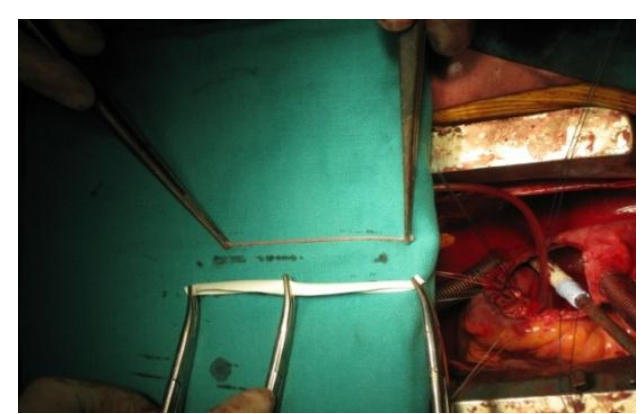

Hình 2.2. Tạo vòng van mềm bằng dải PTFE

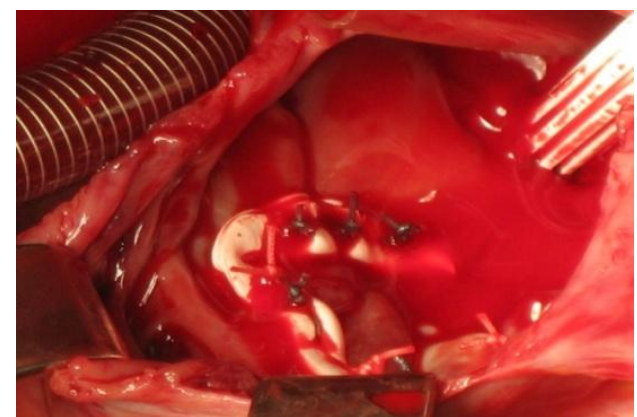

Hình 2.4. Thử lại van ba lá bằng bơm nước

\section{KẾT QUẢ NGHIÊN CỨU VÀ BÀN LUẬN}

\section{1. Đặc điểm bệnh nhân trước phẫu thuật.}

\begin{tabular}{|c|c|}
\hline Đặc điểm bệnh nhân & Thông số của nhóm bệnh nhân \\
\hline Tuối & $47,73 \pm 4,17(20-72)$ \\
\hline Giới (nam/nữ) & $16(53,3 \%) / 14(46,7 \%)$ \\
\hline Tiền sử thấp tim & $24(80 \%)$ \\
\hline NYHA(I/II/III/IV) & $0(0 \%) / 18(60 \%) / 12(40 \%) / 0(0 \%)$ \\
\hline EF trước mổ & $55,21 \pm 7,12(45 \%-76 \%)$ \\
\hline Nhịp tim (rung nhĩ/xoang) & $23(76,67 \%) / 7(23,33 \%)$ \\
\hline \multicolumn{2}{|l|}{ Bênh lý kèm theo: } \\
\hline . Bệnh van hai lá & $15(50 \%)$ \\
\hline Bệnh van ĐMC & $3(1 \%)$ \\
\hline . Cả van $H L$ và van $Đ M C$ & $12(49 \%)$ \\
\hline ĐK thất phải (mm): & $28,52 \pm 4,24(24-38)$ \\
\hline ĐK van ba lá (mm): & $6,35 \pm 1,16(5-7,2)$ \\
\hline ALĐMPTT: & $(43-95 \mathrm{mmHg})$ \\
\hline . ALĐMP $<45 \mathrm{mmHg}$ & $1(\%)$ \\
\hline $.45 \mathrm{mmHg} \leq A L Đ M P \leq 65 \mathrm{mmHg}$ & $19(\%)$ \\
\hline$. A L Đ M P>65 \mathrm{mmHg}$ & $10(\%)$ \\
\hline
\end{tabular}

Nhận xét:

- Các bệnh nhân trong nhóm có độ tuổi trên 20, tỷ lệ nam nũ là tương đương (53,3\% - 46\%), đa số có tiền sư thấp tim (80\%).

- Đa số có NYHA truơóc mổ II/III, EF tương đối tốt, rung nhĩ chiếm tỷ lệ lớn.

- Tát cả các bệnh nhân trước mồ đều có giãn TP, giãn vòng van ba lá và đều tăng áp ĐMPTT (đa số tăng tù vì̀a tới nặng). Rất phù hợp cơ chế hở van ba lá thứ phát. 


\section{2. Đánh giá tình trạng van ba lá trong phẫu thuật:}

\begin{tabular}{ll}
\hline Đặc điểm bệnh nhân & Thông số \\
\hline ĐK van ba lá $(\mathrm{mm})$ & $6,84 \pm 1,22(5,2-7,6)$ \\
Tuần hoàn ngoài cơ thể & \\
. Thời gian chạy máy (phút) & $84,22 \pm 23,46$ \\
. Thời gian cập $Đ M C$ (phút) & $38,24 \pm 7,34$ \\
\hline
\end{tabular}

Nhận xét: - ĐK van 3 lá đánh giá trong phẫu thuật tương đương với đánh giá trên siêu âm trước mổ, cho thấy việc đánh giá $Đ K$ van 3 lá bằng siêu âm có độ tin cậy tốt.

- Thì sứa van 3 lá được tiến hành trong thì tim đập nên chi kéo dài thời gian chạy máy, còn thời gian cặp ĐMC không ảnh huởng.

\section{3. Đánh giá kết quả sau mổ:}

\section{4 .}

3.4.1. Mức độ hở van ba lá sau mổ .

\begin{tabular}{lll}
\hline & Sau mổ 1 tuần & Sau mổ 6 tháng \\
\hline Hở nhẹ van ba lá & $24(80 \%)$ & $22(73,4 \%)$ \\
Hở vừa van ba lá & $6(20 \%)$ & $7(23,3 \%)$ \\
Hở nặng van ba lá & 0 & $1(3,3 \%)$ \\
\hline
\end{tabular}

Nhận xét:

- Truớc mổ các bệnh nhân đều có hở vì̀a tới nặng van ba lá, ngay sau mổ chủ yếu chỉ còn hở nhẹ (80\%), không có bệnh nhân hở van ba lá nạng.

- Sau 6 tháng có một bệnh nhân xuất hiện hở nạnng van ba lá, siêu âm ĐK van ba lá không giãn, rất có thể lá do tiến triển tổn thương van ba lá hậu thấp.

3.4.2. Đánh giá kết quả lâm sàng sau mổ dụa trên chỉ số NYHA.

\begin{tabular}{lll}
\hline & Sau mổ 1 tuần & Sau mổ 6 tháng \\
\hline NYHA I & $18(60 \%)$ & $16(53,3 \%)$ \\
NYHA II & $12(40 \%)$ & $14(46,7 \%)$ \\
NYHA III & 0 & 0 \\
NYHA IV & 0 & 0 \\
\hline
\end{tabular}

3.4.3. Đánh giá các chỉ số sau mổ trên siêu âm.

\begin{tabular}{|c|c|c|}
\hline & Sau mổ 1 tuần & Sau mổ 6 tháng \\
\hline ĐK thất phải (mm) & $28,25 \pm 5,12$ & $24,36 \pm 4,28$ \\
\hline \multicolumn{3}{|l|}{ ALĐMPTT } \\
\hline ALĐMP $<45 \mathrm{mmHg}$ & $20(66,7 \%)$ & $23(76,7 \%)$ \\
\hline $.45 \mathrm{mmHg} \leq A L Đ M P \leq 65 \mathrm{~mm} H g$ & $8(26,7 \%)$ & $7(23,3 \%)$ \\
\hline . $A L Đ M P \geq 65 \mathrm{mmHg}$ & $2(6,6 \%)$ & 0 \\
\hline ĐK van ba lá (mm) & $3,62 \pm 0,58$ & $3,86 \pm 6,78$ \\
\hline
\end{tabular}




\subsection{So sánh các chỉ số siêu âm trước và sau mổ 6 tháng:}

\begin{tabular}{llll}
\hline & Trước mổ & Sau mổ (6 tháng) & $\mathrm{P}$ \\
\hline ĐK thất phải & $28,52 \pm 4,24$ & $24,36 \pm 4,28$ & $<0,05$ \\
ĐK van 3 lá & $6,35 \pm 1,16$ & $3,86 \pm 6,78$ & $<0,05$ \\
ALĐMPTT: & & & \\
$A L Đ M P T T<45 m m H g$ & $1(3,33 \%)$ & $23(76,7 \%)$ & \\
$45 \mathrm{mmHg} \leq A L Đ M P T T \leq 65 \mathrm{mmHg}$ & $19(63,34 \%)$ & $7(23,3 \%)$ & \\
$A L Đ M P T T \geq 65 \mathrm{mmHg}$ & $10(33,33 \%)$ & 0 & \\
\hline
\end{tabular}

Nhận xét:

- Sau 6 tháng, ĐK thất phải và vòng van ba lá đều được thu nhỏ có ý nghĩa thông kê $(P<0,05)$.

Trước mồ ALĐMPTT đa số là tăng vì̀a và nặng. Sau 6 tháng hầu hểt chỉ tăng nhẹ, không có bệnh nhân nào tăng nặng.

\section{BÀN LUẠN}

Qua kết quả nghiên cứu: đa số là tổn thương hậu thấp (80\%). Tất cả các bệnh nhân có hở nặng tới vừa van ba lá trong nhóm nghiên cứu đều: tăng áp ĐMP, giãn vòng van ba lá, giãn thất phải. Điều này rất phù hợp với cơ chế của hở van ba lá thứ phát.

Sửa van ba lá bao gồm nhiều phương pháp, trong đó hay được áp dung nhất là: De Vega, nới rộng mô lá van, Carpentier. Đây là các phương pháp đã được chuẩn hoá và áp dụng tại rất nhiều trung tâm phẫu thuật Tim mạch trên thế giới cũng như Việt Nam.
Tổn thương van ba lá trong bệnh cảnh của van hai lá và van $\mathrm{ĐMC}$ thường là tổn thương cơ năng do dãn vòng van, việc thu nhỏ vòng van ba lá trong phẫu thuật là rất quan trọng.

+ Với phương pháp De Vega, việc phẫu thuật là nhanh gọn, tiết kiệm (do không sử dụng vòng van), kết quả ngắn hạn là tương đối khả quan, tuy nhiên về dài hạn tỷ lệ dãn vòng van tái phát cao, nguyên nhân thất bại hay gặp là do các mũi chỉ khâu vào vòng van sau một thời gian sẽ cắt đứt tổ chức vòng van (5).

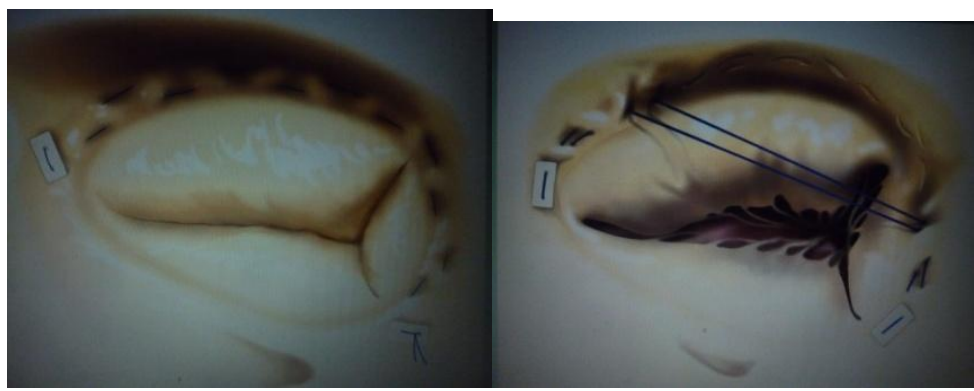

Sưa van 3 lá theo DeVega

+ Với phương pháp Carpentier (thu nhỏ vòng van 3 lá bằng đặt vòng van cứng) hoặc phương pháp Debonis (thu nhỏ vòng van ba lá bằng đặt vòng van mềm), van ba lá được sửa đem lại kết quả rất tốt với cả ngắn hạn và dài hạn(5), tuy nhiên việc sử dụng vòng van cứng với giá thành cao đôi khi gây gánh nặng về mặt kinh tế cho bệnh nhân.

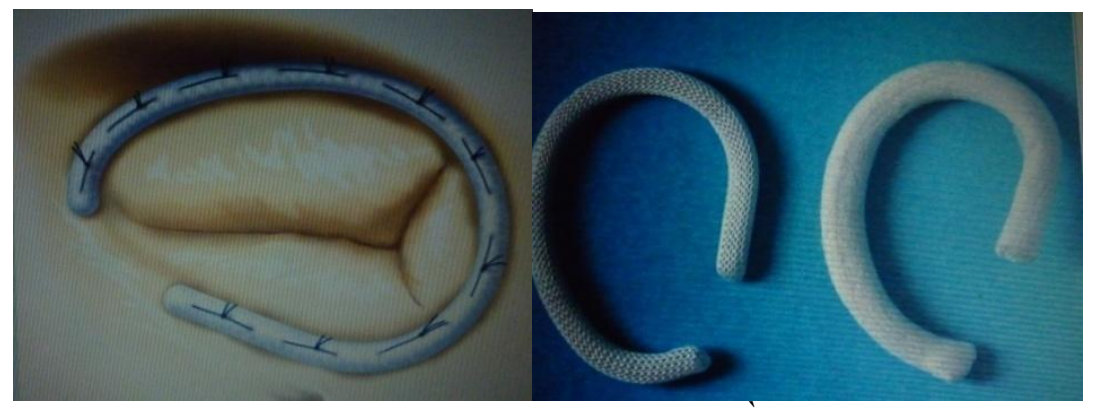

Vòng van cúng Carpentier Vòng van mềm Debonis 
Với việc sử dụng vòng van mềm tạo bởi dải PTFE, chúng ta sẽ đạt được mục đích: thu nhỏ vòng van 3 lá (bị giãn thứ phát), tránh biến chứng hay gặp trong phương pháp DeVega, định hình tương đối vòng van ba lá.

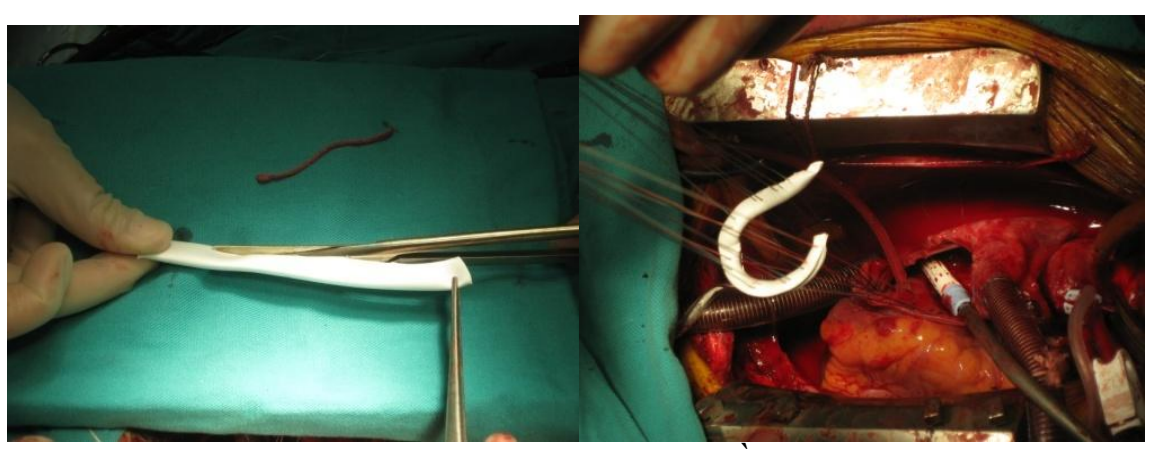

Dái PTFE và vòng van ba lá tạo bằng dải PTFE

Kết quả ngắn hạn rất khả quan, tỷ lệ thành công cao: tỷ lệ hở nặng ngay sau mổ là $0 \%$, sau 6 tháng lá 3,3\% (một bệnh nhân nghi do tổn thương van ba lá hậu thấp). So sánh về các chỉ số liên quan: ĐK vòng van 3 lá, thất phải và ALĐMPTT đều cải thiện rõ rệt. Bên cạnh đó, phương pháp này còn giảm được chi phí phẫu thuật do sử dụng miếng PTFE tận dụng từ các đoạn thừa trong phẫu thuật mạch máu được tiệt trùng lại.

Tuy nhiên về thời gian theo dõi trong nghiên của chúng tôi còn ngắn (6 tháng), cỡ mẫu nhỏ (30 bệnh nhân) nên kết quả nghiên cứu sẽ có nhiều sai số, vì vậy chúng tôi vẫn tiếp tục theo dõi thêm

\section{KẾT LUẬN}

- Đa số tồn thương van ba lá thứ phát gặp trong bệnh cảnh hậu thấp. Hở van ba lá luôn đi kèm: Tăng áp ĐMP, giãn thất phải và giãn vòng van ba lá.
- Sử dụng dải PTFE tạo vòng van mềm trong phẫu thuật sửa van ba lá đem lại kết quả trước mắt là rất khả quan, giảm chi phí phẫu thuật.

- Tuy nhiên, việc theo dõi lâu dài nhóm bệnh nhân này là rất cần thiết.

\section{TÀI LIÊUU THAM KHẢO}

1. Hồ Huỳnh Quang Trí, Phạm Nguyễn Vinh. "Tiến triển của hở van ba lá nặng sau phẫu thuật van hai lá ở người bệnh van tim hậu thấp". Chuyên đề tim mạch học - Hội tim mạch học TP Hồ Chí Minh, tháng $5 / 2010$.

2. Nguyễn Quang Quyền. "Bài giảng giải phẫu người”, tập II. NXB Y học, 1997. Tr 72-86.

3. Frank H.Netter. MD. "Atlas giải phẫu người". NXB Y học 1997. Tr 200-217.

4. Frater. "R. Tricuspid insufficiency. Jthorac Cardiovasc Surg"; 122: 427-429.

5. Jan Dominik, Pavel Zacek. "Heart Valve Surgery”. Springer 2010; P306-339. 